\title{
Simulation of the Dynamic Characteristics of High-Speed Waterjet Using SIMULINK
}

\author{
Guilin Yang
}

School of Electromechanical Engineering, Heze University, Heze 274015, China

Corresponding Author Email: yg188803@ 126.com

https://doi.org/10.18280/ijht.380212

Received: 3 February 2020

Accepted: 5 April 2020

Keywords:
waterjet cutting $\begin{gathered}\text { machine } \\ \text { (WCM), } \\ \text { pressurization }\end{gathered}$ system, dynamic
characteristics, simulation, SIMULINK

\begin{abstract}
This paper takes the Type JJ-I waterjet cutting machine (WCM) as the research object, and establishes a mathematical model for its waterjet pressurization system, then it applies SIMULINK, the dynamic simulation tool package in MATLAB, to simulate the pressure fluctuations of the ultra-high pressure pressurization system and the outlet velocity of the high-speed waterjet. The simulation research showed that, the greater the working pressure, the greater the pressure fluctuations, and the pressure fluctuation rate was decreased. By adjusting the reversing time, the pressure fluctuations increased from $16.01 \mathrm{Mpa}$ to 25.31Mpa. It can be seen that the reversing time had a great impact on pressure fluctuations. Under the same working pressure, the size and the frequency of pressure fluctuations remained unchanged. As the volume of the energy accumulator decreased, the increment in pressure fluctuations increased accordingly. As the volume of the energy accumulator decreased from $0.7 \mathrm{~L}$ to $0.3 \mathrm{~L}$, the pressure fluctuations increased by $13.38 \mathrm{Mpa}$. The simulation research in this paper pointed out a direction for improving the dynamic performance of the waterjet system.
\end{abstract}

\section{INTRODUCTION}

The waterjet technology uses the energy converter - nozzles to convert the energy of the water medium pressure into the kinetic energy of the high-speed waterjet. By adding solid abrasive materials (namely the abrasive) to the waterjet, it could form abrasive water jet (AWJ) with high penetration ability [1-3]. Since AWJ has the ability to cut and process high hardness, high brittleness, high toughness materials and other composite materials that are difficult to process, it has gradually become an advanced machining tool that has been widely used in aerospace, machinery manufacturing, automobile, national defense, military and nuclear industries.

AWJ is essentially a liquid-solid two-phase medium flow. Existing studies show that when AWJ is used to cut materials (especially metal materials), the solid abrasive particles with high kinetic energy play the main role, and the high-speed waterjet plays the supportive role, specifically, the high-speed waterjet accelerates the abrasive particles and cools down the workpiece [4-6]. Therefore, the speed of the waterjet has a decisive effect on the cutting performance of AWJ. Generally speaking, the higher the waterjet speed, the better the acceleration effect of the solid abrasive particles, the greater the kinetic energy obtained by the abrasive particles, and the stronger the cutting ability of AWJ; and vice versa. In terms of manufacturing process, the stronger the cutting ability of AWJ, for a same material, the thicker the workpiece to be cut, and the higher the efficiency, and the better the quality of the cutting section (such as surface roughness and taper). It should be pointed out that changes in the outlet velocity of the waterjet have a great impact on the cutting performance of AWJ, thereby affecting the cutting quality of the workpiece.

Waterjet systems usually adopt two kinds of ultra-high pressure generators: one kind is plunger pump that could be driven directly, the other kind is hydraulic pressure cylinder. Generally speaking, the directly-driven plunger pump has a higher efficiency, while the hydraulic pressure cylinder can generate higher pressure (which is decided by the pressure ratio) $[7,8]$. In fact, for both kinds of the ultra-high pressure generators, the instantaneous output pressures are pulsing, so the outlet velocity of the formed waterjet is unstable [9-14]. In the high-speed precision cutting process, even slight changes in the outlet velocity of the waterjet will leave traces on the cutting section of the workpiece, producing grooves, lines, and tapers, etc. Targeting at this problem, this paper takes the Type JJ-I WCM as the research object, and establishes a mathematical model for its waterjet pressurization system, then it applies SIMULINK, the dynamic simulation tool package in MATLAB, to simulate the pressure fluctuation of the ultra-high pressure pressurization system and the outlet velocity of the high-speed waterjet. Therefore, carrying out studies and tests based on the research results of high-pressure technology is of great significance to the promotion of the design, application and equipment localization of the highpressure waterjet systems.

\section{MATHEMATICAL MODEL OF WATERJET SYSTEM}

\subsection{Flow equation}

According to the flow equation of the orifice, the flow equation of the electromagnetic valve is:

$$
Q_{f}=C_{a} \omega x_{v} \sqrt{\frac{2}{\rho_{o}}\left(P_{s}-P_{1}\right)}
$$


where, $Q_{f}$ is the water flow passing through the electromagnetic valve; $P_{s}$ is the outlet pressure of the pump; $P_{l}$ is the outlet pressure of the electromagnetic valve; $C_{d}$ is the flow coefficient of the reversing valve port; $\omega$ is the area gradient; $x_{v}$ is the displacement of the valve core; $\rho$ is the density of the hydraulic oil; $\omega=\pi D_{l}, D_{l}$ is the diameter of the shoulder ring of the electromagnetic valve core.

\subsection{Flow continuity equation and force balance equation}

The flow continuity equation of the oil inlet chamber of the pressure cylinder is:

$$
Q_{g}=\left(A_{z}-A_{g}\right) v_{\text {piston }}+\frac{V_{1}}{E_{1}} \dot{P}_{1}
$$

where, $Q_{g}$ is the oil inlet flow of the pressure cylinder; $A_{s}$ is the area of the large piston of the pressure cylinder; $A_{g}$ is the area of the piston rod of the pressure cylinder; $v_{\text {piston }}$ is the movement speed of the piston; $V_{l}$ is the volume of the oil inlet chamber, $V_{I}=A_{l} v_{\text {piston }} t, t$ is the movement time of the piston; $\beta_{1}$ is the bulk modulus of the oil; $P_{l}$ is the inlet oil pressure of the pressure cylinder.

The oil supplied by the hydraulic pump flows into the pressure cylinder through the reversing valve, according to the flow continuity equation, there is:

$$
Q_{f}=Q_{g}
$$

According to Newton's law, the force balance equation of the pressure cylinder is:

$$
\left(A_{z}-A_{g}\right) P_{1}=m \dot{v}_{\text {piston }}+B v_{\text {piston }}+P A_{g}
$$

where: $m$ is the mass of the moving part of the pressure cylinder; $B$ is the damping coefficient; $P$ is the pressure of the piston rod cavity;

Ignoring the impact of the one-way valve, the flow continuity equation of the piston rod cavity of the pressure cylinder is:

$$
\dot{V}_{c v}+\frac{V_{c v}}{E_{2}} \dot{P}=-Q_{2}
$$

where: $V_{c v}$ is the volume of the piston rod cavity, $V_{c v}=(h-x) A_{2}$, $h$ is the stroke length of the piston, $x$ is the displacement of the piston, $x=v_{\text {piston }} t ; E_{2}$ is the bulk modulus of water, which is approximately regarded as a constant; $P$ is the water pressure in the piston rod cavity of the pressure cylinder; $Q_{2}$ is the flow of water discharged from the drainage chamber.

\subsection{Pressure stabilization equation}

When $t \leq t_{0}$, the flow continuity equation in the energy accumulator is:

$$
V+\frac{V}{\beta_{2}} P=Q_{2}-Q_{d}
$$

When $t_{0}<t<t_{0}+t_{1}$, during the reversing process of the electromagnetic reversing valve, water is discharged from the energy accumulator (ignoring the volume of the pipeline and the drainage chamber of the pressurizer), then the flow equation is:

$$
V+\frac{V}{\beta_{2}} P=-Q_{d}
$$

where: $t_{0}$ is the stroke time of the piston, $\int_{0}^{t_{0}} v_{\text {piston }} d t=s ; t$ is the reversing time of the electromagnetic valve; $V$ is the volume of the energy accumulator; $Q_{d}$ is the flow of the discharged waterjet, $Q_{d}=C_{a}^{\prime} A_{0} \sqrt{\frac{2 P}{\rho_{w}}}, C_{a}^{\prime}$ is the flow coefficient of the nozzle, $A$ is the cross-sectional area of the nozzle, $\rho_{w}$ is the water density.

During the expansion process of the high-pressure water flowing through the energy accumulator, the volume of the energy accumulator is:

$$
V=\frac{\pi(\varepsilon+D)^{2}}{4} S
$$

where, $\varepsilon$ is the radial elastic strain of the energy accumulator, $\varepsilon=\frac{1}{E} \frac{P D}{2 \delta}, E$ is the elastic modulus of the energy accumulator, $\delta$ is the wall thickness of the energy accumulator, $D$ is the inner diameter of the energy accumulator; $S$ is the stroke of the energy accumulator.

\subsection{Waterjet velocity at nozzle outlet}

As mentioned earlier, the nozzle acts as an energy converter, it converts the pressure energy of the water medium into waterjets with high kinetic energy. According to Bernoulli's equation, the outlet velocity of the waterjet is:

$$
v=44 \sqrt{P}
$$

\section{ESTABLISHMENT OF SIMULATION MODEL OF WATERJET SYSTEM}

System simulation refers to the specific process of studying an existing system or a system under research and design using the system model [15-18]. This method is established based on theories such as control theory, similarity theory, information processing technology and computer technology, etc.; it is a comprehensive experimental science subject that adopts computers and other special physical devices as tools, uses system models to test the real or the false systems, draws on expert experience, statistical data, information and materials to analyze and research the test results, and thereby making the decisions [19-23].

Simulation test includes three stages: modeling stage, model test stage and result analysis stage. Based on the following characteristics of SIMULINK, this study conducted simulation analysis on the dynamic characteristics of the waterjet of WCM.

Based on the above features of the SIMULINK software, the dynamic characteristics of the hydraulic system were simulated. According to Formulas (1)-(7), with the help of the visualization tools provided by SIMULINK, a SIMULINK simulation model was constructed. Formula (1) was 
encapsulated in the flow equation module of the electromagnetic valve; Formula (2) was encapsulated in the flow equation module of the oil inlet chamber of the pressure cylinder; Formula (4) was encapsulated in the force balance equation module of the pressurizer; Formula (5) was encapsulated in the flow equation module of the drainage chamber of the pressurizer; Formula (6) was encapsulated in the flow equation module of the energy accumulator; Formula (7) was encapsulated in module of the energy accumulator system, as shown in Figure 1. Based on the Type JJ-I WCM, the system simulation structure parameters are shown in Table 1 .

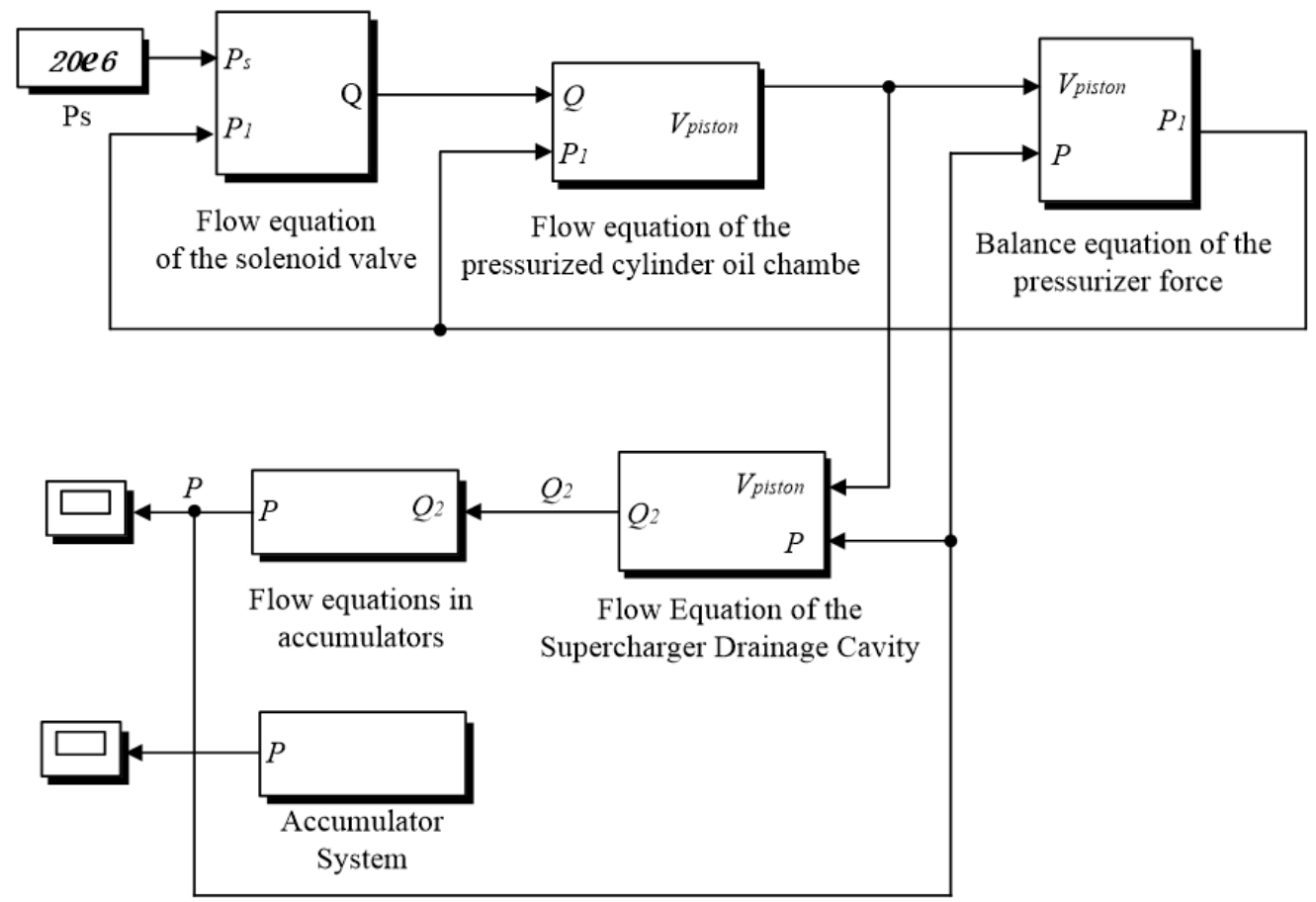

Figure 1. Simulink simulation model of the target pressurization system

Table 1. Simulation parameters of the waterjet system

\begin{tabular}{|c|c|c|c|c|c|c|c|}
\hline Parameter name & Symbol & Unit & Value & Parameter name & Symbol & Unit & Value \\
\hline $\begin{array}{c}\text { The mass of the electromagnetic } \\
\text { valve core }\end{array}$ & $\mathrm{m}$ & $\mathrm{kg}$ & 0.15 & $\begin{array}{l}\text { Elastic modulus of ultra-high } \\
\text { pressure energy accumulator }\end{array}$ & $E$ & $\mathrm{GPa}$ & 205 \\
\hline Flow coefficient & $C_{a}$ & & 0.6 & Piston stroke & $h$ & $\mathrm{~mm}$ & 80 \\
\hline Oil density & $\rho_{o}$ & $\mathrm{Kg} / \mathrm{m}^{3}$ & 869 & Bulk modulus of the oil & $E_{1}$ & $\mathrm{~N} / \mathrm{m}^{2}$ & $1.5 \times 10^{9}$ \\
\hline $\begin{array}{l}\text { Diameter of the shoulder ring of } \\
\text { the electromagnetic valve core }\end{array}$ & $D_{l}$ & $\mathrm{~mm}$ & 5.176 & Bulk modulus of the water & $E_{2}$ & $\mathrm{~N} / \mathrm{m}^{2}$ & $4.1 \times 10^{9}$ \\
\hline Electromagnetic valve size & $l_{a}$ & $\mathrm{~mm}$ & 0.28 & $\begin{array}{l}\text { Mass of the pressure cylinder } \\
\text { piston }\end{array}$ & $m$ & $\mathrm{~kg}$ & 2.96 \\
\hline $\begin{array}{l}\text { Area of the large piston of the } \\
\text { pressure cylinder }\end{array}$ & $A_{z}$ & $\mathrm{~m}^{2}$ & $3.77 \times 10^{-3}$ & Damping coefficient & $B$ & & 10000 \\
\hline Water density & $\rho_{w}$ & $\mathrm{Kg} / \mathrm{m}^{3}$ & $1.0 \times 10^{3}$ & $\begin{array}{l}\text { Stroke of the ultra-high } \\
\text { pressure energy accumulator }\end{array}$ & $H$ & $\mathrm{~mm}$ & 500 \\
\hline $\begin{array}{l}\text { Area of the piston rod of the } \\
\text { pressure cylinder }\end{array}$ & $A_{g}$ & $\mathrm{~m}^{2}$ & $3.5 \times 10^{-4}$ & $\begin{array}{l}\text { Inner diameter of the ultra-high } \\
\text { pressure energy accumulator }\end{array}$ & $D$ & $\mathrm{~mm}$ & 41 \\
\hline $\begin{array}{l}\text { Reversing time of the } \\
\text { electromagnetic valve }\end{array}$ & $t$ & $\mathrm{~s}$ & 0.16 & $\begin{array}{c}\text { Cross-sectional area of the } \\
\text { nozzle }\end{array}$ & $A$ & $\mathrm{~m}^{3}$ & $3.15 \times 10^{-8}$ \\
\hline $\begin{array}{l}\text { Wall thickness of ultra-high } \\
\text { pressure energy accumulator }\end{array}$ & $\delta$ & $\mathrm{mm}$ & 4.95 & Flow coefficient of the nozzle & $C_{a}^{\prime}$ & & 0.68 \\
\hline
\end{tabular}

\section{SIMULATION RESULTS}

\subsection{WCM composition and parameters, and the principle of high-pressure generator}

The composition of the Type JJ-I WCM is shown in Figure 2. It is mainly composed of flow-changeable plunger pump, relief valve, electromagnetic reversing valve, reciprocating pressure cylinder, ultra-high pressure energy accumulator, abrasive supply system, nozzle, and other components.
According to the parameters of the Type JJ-I WCM, the maximum outlet pressure of the hydraulic pump is $32.6 \mathrm{MPa}$, the pressure ratio of the pressurizer is 10:1, then the pressurizer can boost the pressure of ordinary water to more than $300 \mathrm{MPa}$; equipped with a $0.26 \mathrm{~mm}$ diameter jewel nozzle, the outlet velocity of the waterjet can reach $800 \mathrm{~m} / \mathrm{s}$.

The Type JJ-I WCM adopted the pressure cylinder ultrahigh pressure generator, as shown in Figure 2. The system consists of a hydraulic oil circuit and a high-pressure water circuit. The plunger pump pumps the pressure oil which flows 
into the right piston cavity of pressure cylinder 5 through the left position of the 3-working position 4-port reversing valve 3 , and the hydraulic oil in the left piston cavity of the pressure cylinder 5 returns to the oil tank through the left position of the reversing valve 3 , and the piston of the pressure cylinder moves to the left under the action of the pressure oil. On the one hand, the plunger in the pressure cylinder pressurizes the water medium on the left side of the pressure cylinder, and the ultra-high pressure water runs through the one-way valve 4 and energy accumulator 7 , and then ejects out from nozzle 15; on the other hand, the make-up pump injects low-pressure water into the ultra-high pressure cylinder on the right side of the pressure cylinder through the one-way valve group 6 . When the piston moves left to the end of the stroke, the Hall proximity switch sends out an electric signal, the electromagnetic reversing valve 3 is switched to the right position, the piston of the pressure cylinder moves in the opposite direction (to the right) and pressurizes the water in the right side of the ultra-high pressure cylinder, then the highpressure water flows into the energy accumulator through the one-way valve group 6 , and ejects out from nozzle 15 . Such processes are repeated over and over again to form a continuous high-speed waterjet.

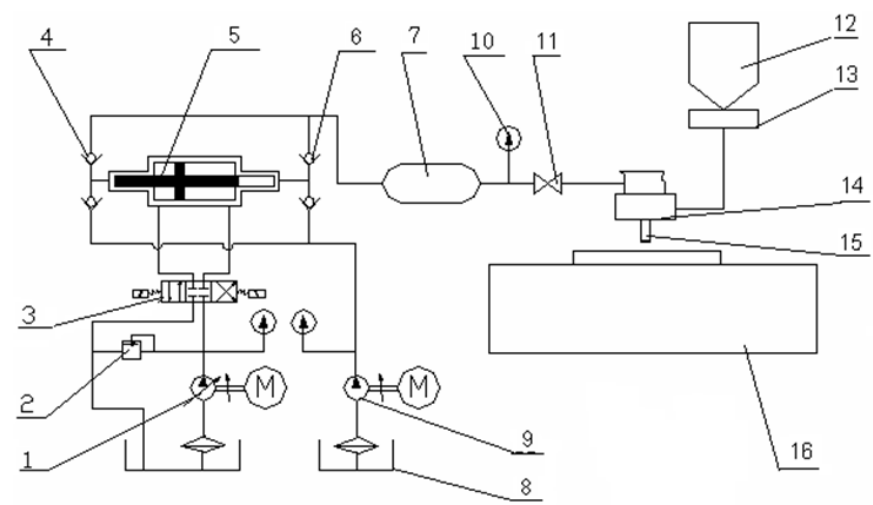

1. Hydraulic plunger pump; 2. Relief valve; 3 . Electromagnetic reversing valve; $4 \& 6$. One-way valve group; 5 . Pressurizer; 7 . Ultra-high pressure energy accumulator; 8 . Water tank; 9. Water pump; 10. Pressure gauge; 11. Switch valve; 12. Abrasive box; 13. Abrasive valve; 14. Water nozzle; 15. Abrasive mixing pipe; 16 . Workbench

Figure 2. Pressurization system of Type JJ-I WCM

\subsection{Simulink simulation results}

Using the SIMULINK simulation model, the obtained simulation results are shown in the following figures. Figure 3 shows the pressure fluctuation curves under different inlet oil pressures; Figure 4 shows the waterjet velocities at different working pressures; Figure 5 shows the pressure fluctuation curves under different pressure ratios and reversing times; Figure 6 shows the pressure fluctuation curves under different energy accumulator volumes.

(1) In Figure 3, p1-p5 are the pressure fluctuations at the nozzle outlet when the inlet oil pressure was $100 \mathrm{Mpa}, 150 \mathrm{Mpa}$, $200 \mathrm{Mpa}, 240 \mathrm{Mpa}$, and $300 \mathrm{Mpa}$, respectively. It can be seen from the figure that the greater the working pressure, the greater the pressure fluctuations during reversing, and the more frequent the pressure fluctuations. The pressure fluctuation is defined as: $\eta=$ working pressure-pressure in the energy accumulator at the end of reversing, the pressure fluctuation rate is defined as: $a=\eta /$ working pressure, then the pressure fluctuations of $\mathrm{p} 1-\mathrm{p} 5$ were calculated to be $13.16 \mathrm{Mpa}$,
17.56Mpa, 18.98Mpa, 21.99Mpa, and 25.61 Mpa, respectively; and the pressure fluctuation rates of $\mathrm{p} 1-\mathrm{p} 5$ were calculated to be $13.5 \%, 11.39 \%, 10.06 \%, 9.55 \%, 8.52 \%$, respectively. It can be seen that the greater the working pressure, the greater the pressure fluctuations, and the pressure fluctuation rate decreased accordingly. According to data and analysis, Figure 3 is discussed from the perspective of time as: the greater the inlet pressure, the greater the pressure fluctuations, and the smaller the time interval between two fluctuations, that is, the greater the frequency of the pressure fluctuations.

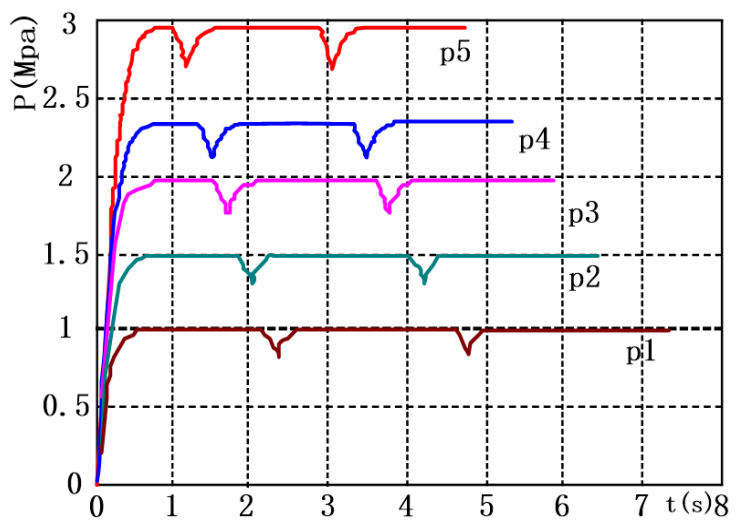

Figure 3. The pressure fluctuation curve under different inlet oil pressures

(2) In Figure 4, v1-v5 are the outlet velocities of the waterjet corresponding to pressures $\mathrm{p} 1-\mathrm{p} 5$, from the figure, it can be seen that, the greater the working pressure, the higher the waterjet velocity, the greater the fluctuations of the velocity and the fluctuation frequency, therefore, when the working pressure is higher, although the cutting performance is improved, the waterjet is becoming increasingly unstable. According to data and analysis, it can be seen from Figure 4 that the greater the outlet velocity of the waterjet, the greater the fluctuations of the velocity, and the greater the fluctuation frequency.

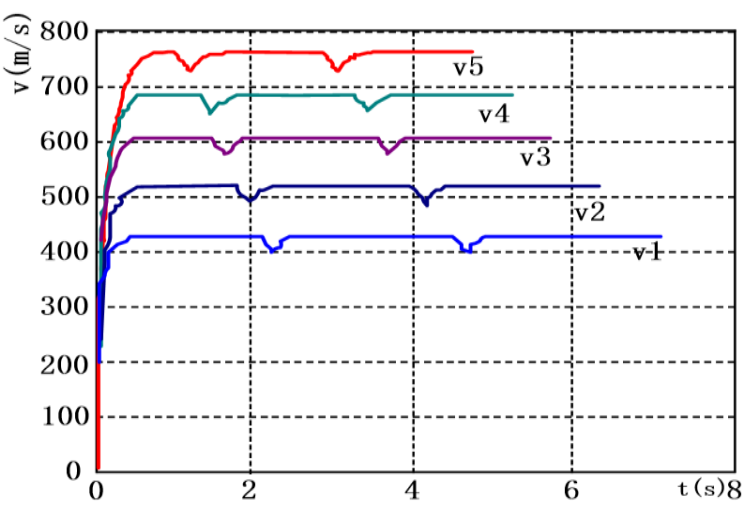

Figure 4. The waterjet velocity curve at different working pressures

(3) In Figure 5, the corresponding situations of 1, 2, 3 and 4 are: $P_{s}=20 \mathrm{Mpa}, \mathrm{b}=10: 1$ (pressure ratio is defined as: $\mathrm{b}=\left(\mathrm{A}_{\mathrm{z}^{-}}\right.$ $\left.\mathrm{A}_{\mathrm{g}}\right) / \mathrm{A}_{\mathrm{g}}$ ), reversing time of electromagnetic valve $t_{l}=0.16 \mathrm{~s}$; $P_{s}=20 \mathrm{Mpa}, \mathrm{b}=8: 1$, reversing time of electromagnetic valve $t_{l}=0.16 \mathrm{~s} ; \quad P_{s}=20 \mathrm{Mpa}, \quad b=10: 1, \quad$ reversing time of electromagnetic valve $t_{l}=0.2 \mathrm{~s} ; P_{s}=20 \mathrm{Mpa}, b=8: 1$, reversing time of electromagnetic valve $t_{l}=0.16 \mathrm{~s}$; the inlet oil pressures of situations 1 and 2 are the same. Under the condition that the 
pressure ratio was reduced, the working pressure decreased, and the pressure fluctuations decreased accordingly; as the pressure ratio was reduced from 10:1 to $8: 1$, the pressure fluctuations decreased by $2.87 \mathrm{Mpa}$; In situation 3 , the reversing time was increased from $0.16 \mathrm{~s}$ to $0.2 \mathrm{~s}$, the pressure fluctuations increased from 19.88 to 25.31 , it can be seen that the reversing time had a great impact on the pressure fluctuations. Situation 4 reduced the pressure ratio by increasing the inlet oil pressure to realize the same working pressure, and keep the size and frequency of the pressure fluctuations unchanged. According to data and analysis, the shorter the reversing time of the electromagnetic reversing valve, the smaller the pressure fluctuations, and the more stable the system.

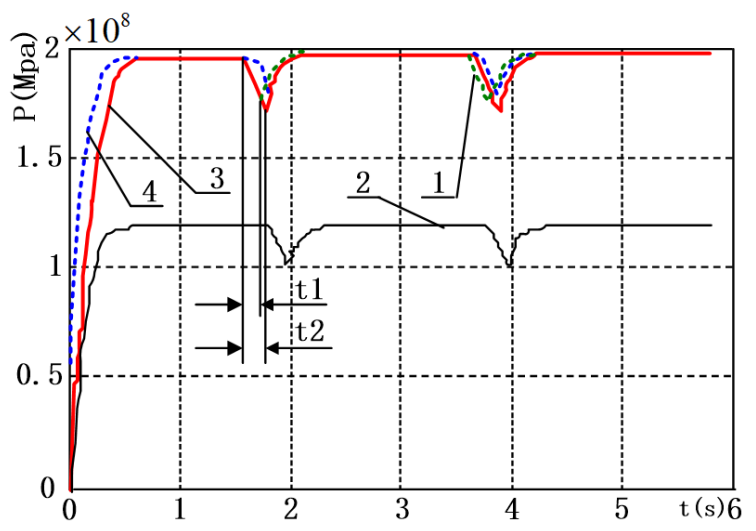

Figure 5. The pressure fluctuation curve under different pressure ratios and reversing times

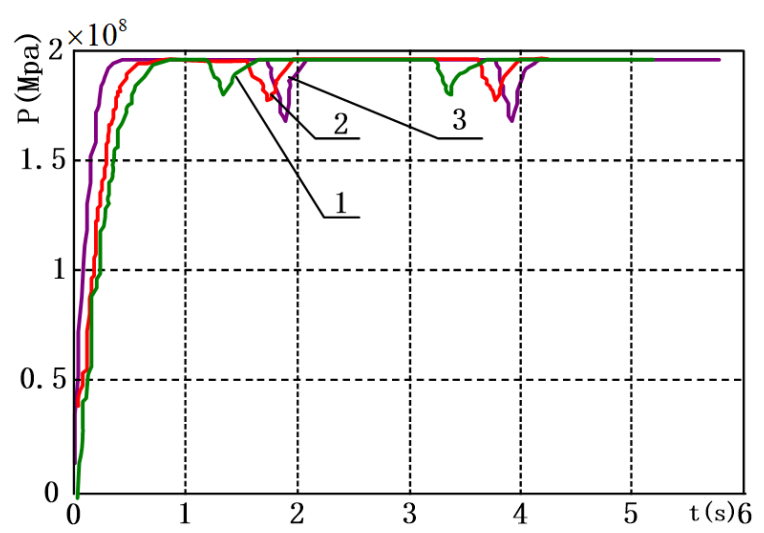

Figure 6. The pressure fluctuation curve under different energy accumulator volumes

(4) In Figure 6, 1, 2, and 3 are the corresponding pressure fluctuations when the accumulator volume was $0.7 \mathrm{~L}, 0.50 \mathrm{~L}$, and $0.3 \mathrm{~L}$ under the same working pressure, pressure ratio, and reversing time. It can be seen from the figure that, the smaller the energy accumulator volume, the greater the pressure fluctuations, when the accumulator volume decreased from $0.7 \mathrm{~L}$ to $0.5 \mathrm{~L}$, the pressure fluctuations increased by $5.02 \mathrm{Mpa}$; when the accumulator volume decreased from $0.5 \mathrm{~L}$ to $0.3 \mathrm{~L}$, the pressure fluctuations increased by $8.36 \mathrm{Mpa}$, it can be seen that, with the decrease of the energy accumulator volume, the increment in the pressure fluctuations increased accordingly. According to data and analysis, the three curves of 1, 2 and 3 in Figure 6 showed that when the energy accumulator volume was $0.7 \mathrm{~L}$ (curve 1), the pressure fluctuations were the smallest; when the energy accumulator volume was $0.3 \mathrm{~L}$ (curve 3 ), the pressure fluctuations were the largest.
(5) According to the Simulink simulation of the above 4 sets of data, in order to achieve the best processing or cutting quality, the values of the four parameters of reversing time, waterjet pressure, outlet velocity and energy accumulator volume can be adjusted, these research findings point out a direction for improving the dynamic performance of the waterjet system.

\section{CONCLUSION}

In this paper, MATLAB/SIMULINK was adopted to simulate the waterjet system pressure and waterjet velocity of the Type JJ-I WCM. In terms of the simulation results, due to the large pressure fluctuations, using hydraulic system to increase pressure would make the waterjet outlet velocity unstable, and it has a great impact on the cutting precision of WCM. In such case, the pressure and velocity fluctuations could be reduced by decreasing the reversing time of the reversing valve, increasing the energy accumulator volume appropriately, and adjusting the pressure ratio according to the specific situations. In order to further improve the processing quality of WCM, especially the quality of waterjet precision processing, it is necessary to reduce the water pressure fluctuations and ensure the stability of the waterjet outlet velocity by optimizing the system structure parameters and reducing the water pressure fluctuations. To meet the abovementioned cutting quality and system stability, the following measures should be taken:

(1) Under the condition that the pressure ratio, working pressure and reversing time remain unchanged, energy accumulators with greater volume should be selected;

(2) The greater the working pressure of the system, the greater the pressure fluctuations, and the pressure fluctuation rate is decreased; to achieve better cutting quality, the pressure that is slightly greater than the middle value should be selected as the working pressure;

(3) Decreasing pressure ratio and reversing time of the electromagnetic reversing valve could reduce the pressure fluctuations, and make the quality of the cutting surface uniform.

(4) The higher the waterjet velocity, the greater the pressure fluctuations and the smaller the pressure fluctuation rate, the pressure that is slightly greater than the middle value should be selected as the working pressure;

(5) The factors with an impact on the stability of the waterjet system from high to low are: the reversing time of the electromagnetic reversing valve, the waterjet pressure, the waterjet velocity, and the pressure ratio.

\section{REFERENCES}

[1] Hou, R., Huang, C., Zhu, H. (2017). Experimental study on pulsation behavior of the ultrasonic vibration-assisted abrasive waterjet. The International Journal of Advanced Manufacturing Technology, 91(9-12): 3851-3859. https://doi.org/10.1007/s00170-017-0011-0

[2] Deng, C., Yeo, H., Ki, H. (2020). Electrodynamic simulation of laser beam propagation in waterjet-guided laser processing. Optics Express, 28(8): 11128-11143. https://doi.org/10.1364/OE.389497

[3] Vincent, H., Wells, L., Tarazaga, P., Camelio, J. (2015). Trojan detection and side-channel analyses for cyber- 
security in cyber-physical manufacturing systems. Procedia Manufacturing, 1: 77-85. https://doi.org/10.1016/j.promfg. 2020. 05.085

[4] Mao, S., Huang, Z.W., Tian, S.C., Zhang, Y., Gao, S.. Jia, Y.P. (2020). CFD analysis and field observation of tool erosion caused by abrasive waterjet fracturing. Petroleum Science, 17: 701-711. https://doi.org/10.1007/s12182-020-00425-1

[5] Arab, P.B., Celestino, T.B. (2020). A microscopic study on kerfs in rocks subjected to abrasive waterjet cutting. Wear, 448:

203210 . https://doi.org/10.1016/j.wear.2020.203210

[6] Desbiolles, J., Taki, O. Butler, G. (2020). A laboratory evaluation of waterjet cutting of crop residue using the Aqua-Till@ liquid coulter. Soil and Tillage Research, 198: 104537. https://doi.org/10.1016/j.still.2019.104537

[7] Jäger, L., Linzenbold, W., Fech, A., Enderle, M., Abruzzese, T., Stenzl, A., Aicher, W.K. (2020). A novel waterjet technology for transurethral cystoscopic injection of viable cells in the urethral sphincter complex. Neurourology and Urodynamics, 39(2): 594-602. https://doi.org/10.1002/nau.24261

[8] Tripathi, R., Hloch, S., Chattopadhyaya, S., Klichová, D., Klich, J. (2020). Influence of frequency change during sandstone erosion by pulsed waterjet. Materials and Manufacturing Processes, 35(2): 187-194. https://doi.org/10.1080/10426914.2019.1669800

[9] Guo, J., Chen, Z., Dai, Y. (2020). Numerical study on self-propulsion of a waterjet propelled trimaran. Ocean Engineering, 195: 106655 https://doi.org/10.1016/j.oceaneng.2019.106655

[10] Qiang, Z., Miao, X., Wu, M., Sawhney, R. (2018). Optimization of abrasive waterjet machining using multiobjective cuckoo search algorithm. The International Journal of Advanced Manufacturing Technology, 99(58): 1257-1266. https://doi.org/10.1007/s00170-01904578-1

[11] Misrai, V., Rijo, E., Zorn, K.C., Barry-Delongchamps, N., Descazeaud, A. (2019). Waterjet ablation therapy for treating benign prostatic obstruction in patients with small-to medium-size glands: 12-month results of the first french aquablation clinical registry. European Urology, 76(5): 667-675 https://doi.org/10.1016/j.eururo.2019.06.024

[12] Esmailian, E., Gholami, H., Røstvik, H.N., Menhaj, M.B. (2019). A novel method for optimal performance of ships by simultaneous optimisation of hull-propulsion-BIPV systems. Energy Conversion and Management, 197: 111879. https://doi.org/10.1016/j.enconman.2019.111879

[13] Oh, T.M., Joo, G.W., Cho, G.C. (2019). Effect of abrasive feed rate on rock cutting performance of abrasive waterjet. Rock Mechanics and Rock Engineering, 52(9): 3431-3442. https://doi.org/10.1007/s00603-019-01784-x
[14] Wang, Y., Zhang, Z., Zhang, G., Wang, B., Zhang, W. (2018). Study on immersion waterjet assisted laser micromachining process. Journal of Materials Processing Technology, 262: 290-298. https://doi.org/10.1016/j.jmatprotec.2018.07.004

[15] Balamurugan, K., Uthayakumar, M., Gowthaman, S., Pandurangan, R. (2018). A study on the compressive residual stress due to waterjet cavitation peening. Engineering Failure Analysis, 92: 268-277. https://doi.org/10.1016/j.engfailanal.2018.05.012

[16] Lv, Z., Hou, R., Tian, Y., Huang, C., Zhu, H. (2018). Numerical study on flow characteristics and impact erosion in ultrasonic assisted waterjet machining. The International Journal of Advanced Manufacturing Technology, 98(1-4): 373-383. https://doi.org/10.1007/s00170-018-2271-8

[17] Liu, D., Zhu, H., Huang, C., Wang, J., Yao, P. (2016). Prediction model of depth of penetration for alumina ceramics turned by abrasive waterjet - finite element method and experimental study. The International Journal of Advanced Manufacturing Technology, 87(912): 2673-2682. https://doi.org/10.1007/s00170-0168600-x

[18] Yue, Z., Huang, C., Zhu, H., Wang, J., Yao, P., Liu, Z. (2014). Optimization of machining parameters in the abrasive waterjet turning of alumina ceramic based on the response surface methodology. The International Journal of Advanced Manufacturing Technology, 71(912): 2107-2114. https://doi.org/10.1007/s00170-0145624-y

[19] Finnie, I., Stevick, G.R., Ridgely, J.R. (1992). The influence of impingement angle on the erosion of ductile metals by angular abrasive particles. Wear, 152(1): 9198. https://doi.org/10.1016/0043-1648(92)90206-N

[20] Lv, Z., Huang, C., Zhu, H., Wang, J., Wang, Y., Yao, P. (2015). A research on ultrasonic-assisted abrasive waterjet polishing of hard-brittle materials. The International Journal of Advanced Manufacturing Technology, 78(5-8): 1361-1369. https://doi.org/10.1007/s00170-014-6528-6

[21] Qi, H., Wen, D., Lu, C., Li, G. (2016). Numerical and experimental study on ultrasonic vibration-assisted micro-channelling of glasses using an abrasive slurry jet. International Journal of Mechanical Sciences, 110: 94107. https://doi.org/10.1016/j.ijmecsci.2016.03.013

[22] Nouraei, H., Wodoslawsky, A., Papini, M., Spelt, J. K. (2013). Characteristics of abrasive slurry jet micromachining: A comparison with abrasive air jet micromachining. Journal of Materials Processing Technology, 213(10): $1711-1724$ https://doi.org/10.1016/j.jmatprotec.2013.03.024

[23] Sheldon, G.L., Finnie, I. (1966). The mechanism of material removal in the erosive cutting of brittle materials Journal of Manufacturing Science and Engineering, 88(4): 393-399. https://doi.org/10.1115/1.3672667 